\title{
Innate and Adaptive Immune Responses Against Microsporidia Infection in Mammals
}

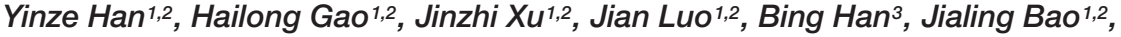 \\ Guoqing Pan ${ }^{1,2}$, Tian $\mathrm{Li}^{1,2 *}$ and Zeyang Zhou ${ }^{1,2,4 *}$
}

${ }^{1}$ State Key Laboratory of Silkworm Genome Biology, Southwest University, Chongqing, China, ${ }^{2}$ Chongqing Key Laboratory of Microsporidia Infection and Control, Southwest University, Chongqing, China, ${ }^{3}$ Department of Pathology, Albert Einstein College of Medicine, The Bronx, NY, United States, ${ }^{4}$ College of Life Sciences, Chongqing Normal University, Chongqing, China

OPEN ACCESS

Edited by:

Lihua Xiao,

South China Agricultural University,

China

Reviewed by:

Louis Weiss,

Albert Einstein College of Medicine,

United States

Hicham El Alaoui,

Université Clermont Auvergne, France

Tian Luo,

The University of Texas Medical Branch at Galveston, United States

Majid Pirestani,

Tarbiat Modares University, Iran

*Correspondence:

Tian Li

lit@swu.edu.cn

Zeyang Zhou

zyzhou@swu.edu.cn

Specialty section:

This article was submitted to Infectious Diseases,

a section of the journal

Frontiers in Microbiology

Received: 13 September 2019

Accepted: 04 June 2020

Published: 26 June 2020

Citation:

Han Y, Gao H, Xu J, Luo J,

Han B, Bao J, Pan G, Li T and Zhou Z (2020) Innate and Adaptive Immune

Responses Against Microsporidia

Infection in Mammals.

Front. Microbiol. 11:1468.

doi: 10.3389/fmicb.2020.01468
Microsporidia are obligate intracellular and eukaryotic pathogens that can infect immunocompromised and immunocompetent mammals, including humans. Both innate and adaptive immune systems play important roles against microsporidian infection. The innate immune system can partially eliminate the infection by immune cells, such as gamma delta T cell, natural killer cells (NKs), macrophages and dendritic cells (DCs), and present the pathogens to lymphocytes. The innate immune cells can also prime and enhance the adaptive immune response via surface molecules and secreted cytokines. The adaptive immune system is critical to eliminate microsporidian infection by activating cytotoxic T lymphocyte $(\mathrm{CTL})$ and humoral immune responses, and feedback regulation of the innate immune mechanism. In this review, we will discuss the cellular and molecular responses and functions of innate and adaptive immune systems against microsporidian infection.

Keywords: microsporidia, mammal host, immune response, innate immunity, adaptive immunity

\section{INTRODUCTION}

Microsporidia are obligate intracellular parasites that infect nearly all vertebrates and invertebrates, including immunocompetent and immunocompromised humans. The Microsporidia phylum is composed of at least 200 genera and 1400 species (Cali et al., 2017). At least 17 species within nine genera (Anncaliia, Encephalitozoon, Enterocytozoon, Microsporidium, Nosema, Pleistophora, Trachipleistophora, Tubulonosema, Vittaforma) of microsporidia have been reported to be able to infect humans (Fayer and Santin-Duran, 2014; Han and Weiss, 2017). The humaninfecting microsporidia are recognized as opportunistic pathogens, and frequently reported in immunocompetent and immunocompromised individuals, such as AIDS patients, cancer patients, transplant recipients, children and the elderly (Lores et al., 2002; Tumwine et al., 2002; Mor et al., 2009; Abu-Akkada et al., 2015; Wang et al., 2018; Ghoyounchi et al., 2019). Moreover, some microsporidia have a broad host range and can be transmitted among animals and humans, leading to zoonotic or interspecies transmission of microsporidiosis (Li et al., 2019; Udonsom et al., 2019).

When infecting, microsporidian spores extrude a polar tube, through which sporoplasms inside the spores are transported into host cells for development and proliferation (Franzen, 2005; Franzen et al., 2005b; Han et al., 2020). Inside host cell, the pathogen has to fight against host immune 
systems, including innate immunity and adaptive immunity. A few years ago, several reviews summarized studies in the early time on the immune responses of mammals against microsporidian infections (Khan et al., 2001; Ghosh and Weiss, 2012; Valencakova and Halanova, 2012). These very early analyses had partially indicated that both immunities are crucial to the resistance against microsporidian infections, and had found that immune cells including macrophages, dendritic cells (DCs) and CD8 $+\mathrm{T}$ cell, and cytokines like IL-12 and IFN- $\gamma$ are activated and contribute to the immune defense (Mathews et al., 2009). In recent years, some new and further studies have revealed more cellular and molecular interactions between host immune system and microsporidia. In this review, we will systematically discuss the cellular and molecular responses to microsporidian infections from aspects of innate and adaptive immunities, respectively.

\section{INNATE IMMUNE RESPONSE TO MICROSPORIDIAN INFECTION}

The innate immune system serves as the first line of defense and plays important roles in non-specific responses against infections. The innate immune system is composed of tissue barrier, innate immune cells, innate immune molecules, and cytokines (Beutler, 2004; Turvey and Broide, 2010; Sokol and Luster, 2015). The innate immune cells including macrophages, DCs, Natural Killer Cells (NKs) and innate-like lymphocytes have been proved to be essential for responses against microsporidian infections (Didier et al., 2010; Lawlor et al., 2010; Moretto et al., 2012). The innate immunity cannot completely clear microsporidian infection, but is necessary to activate the responses of adaptive immunities for a clearance.

\section{Macrophage Response to Microsporidian Infection}

Macrophages originate from blood monocytes, differentiate in tissues, and are involved in the detection, phagocytosis and destruction of harmful organisms. Macrophages can also present antigens to $\mathrm{T}$ cells and initiate inflammation by releasing cytokines to activate other immune cells. During microsporidian infection, macrophages can recognize the pathogens via pattern recognition receptors (PRRs) on the surface (Fischer et al., 2008a), and subsequently active defense mediators, such as chemokines, cytokines, reactive nitrogen, and radical oxygen, to control pathogen dissemination (Mathews et al., 2009). Macrophages are highly plasticity, can be activated and generate classically activated (M1) and alternatively activated (M2) types according to the activation state and functions, respectively (Martinez and Gordon, 2014). IFN- $\gamma$ and lipopolysaccharide (LPS) are important activators for polarization of M1, which has intense phagocytic activity and higher microbicidal activity with NO and can secrete IL-12 and IFN- $\gamma$ (Martinez and Gordon, 2014). It has been found that M1 can significantly reduce Encephalitozoon infection (Didier and Shadduck, 1994; Didier, 1995; Fischer et al., 2008b) depending on reactive nitrogen species (RNS) and reactive oxygen species (ROS)
(Didier, 1995; Didier et al., 2010; Gonzalez-Machorro et al., 2019; Figure 1). The RNS- and ROS-deficient mice were shown to bear significantly higher peritoneal pathogen load and need longer time to eliminate the infection compared to the wild type of mice (Didier et al., 2010). Nonetheless, the deficient mice finally survived against Encephalitozoon cuniculi infection (Didier et al., 2010). Moreover, the phagocytosis of microsporidia significantly increased in LPS-activated murine macrophages, and the growth of pathogens inside the macrophages was inhibited, while the inhibitory effect lost after $72 \mathrm{~h}$ (GonzalezMachorro et al., 2019). These findings suggest that macrophages can control microsporidian infection to a certain extent, but the complete elimination likely requires other immunities. In addition, it was found that macrophage activities were associated with B-1 cells in microsporidian infection. In mice with B-1 cells, peritoneal macrophages had an M1 profile. In B-1 cell deficient mice, however, E. cuniculi modulated macrophages to M2, which is less phagocytic capacity and index and microbicidal activity, and inside which spore germination was observed, suggesting that B-1 cells are important in the modulation of macrophage in E. cuniculi infection (Pereira et al., 2019).

In fact, studies have tried to understand that how microsporidia escape the macrophage immunity. Early studies proved that microsporidian spores in vacuoles were able to block phagosome acidification and fusion with secondary lysosomes (Weidner and Sibley, 1985; Figure 1). Sporecontaining phagocytic vacuoles fused with lysosomes can kill partial pathogens, while some sporoplasms can still escape from maturing lysosomes so that enter into host cytoplasm for successful infection (Franzen, 2005; Franzen et al., 2005b). When failing to inhibit the proliferation of microsporidia, macrophages can release chemokines (CCL3, CCL4) with TLR2-NF- $\mathrm{B}$ signaling pathway to recruit phagocytes (Fischer et al., 2008a; Figure 1). However, this recruitment mechanism can be hijacked by the pathogens for infecting more monocytes and expanding the monocyte-derived-macrophage infections (Fischer et al., 2007). Meanwhile, the macrophage itself may also be hijacked as a "Trojan horse" to carry the parasites to other parts of the host body and spread the infection (Mathews et al., 2009). Furthermore, the macrophage immunity can be modulated by microsporidia via cytokines. In human macrophages infected with Encephalitozoon, the expression of IL-10 increased (Franzen et al., 2005a). This is consistent with the later study by Pereira et al. (2019) that macrophages were polarized to M2 type, in which the IL-10 expression is upregulated and the pathogens can escape from killing. Besides, the IL-10 belongs to an antiinflammatory cytokine and can inhibit the production of nitric oxide and activity of macrophages and Th1 cells during infection (Popi et al., 2004; Couper et al., 2008). It was documented that early expression of IL-10 delayed the production of IFN- $\gamma$ (Braunfuchsova et al., 1999), which was found to play an important role in macrophage-activating and resisting the microsporidian infection (Achbarou et al., 1996; El Fakhry et al., 1998, 2001; Khan and Moretto, 1999; Rodriguez-Tovar et al., 2016). 


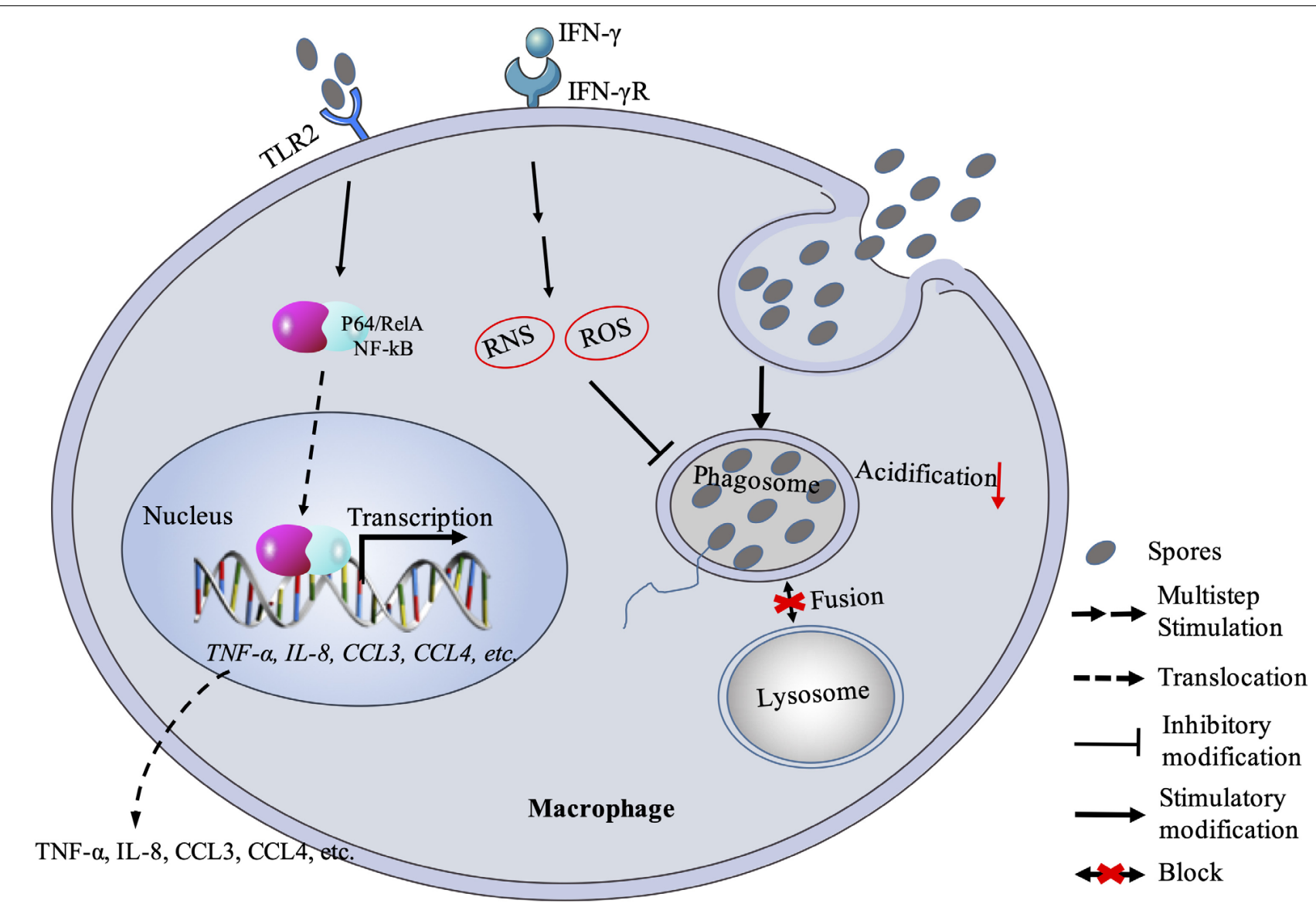

FIGURE 1 | Macrophage response against microsporidian infection. Macrophage recognizes microsporidia via MyD88-dependent TLR2 and stimulates downstream expression of cytokines and chemokines. Macrophage can also kill the pathogen with RNS and ROS mechanism. Besides, microsporidia can block the fusion between phagosome and lysosome. RNS, reactive nitrogen species; ROS: reactive oxygen species.

\section{DCs Response to Microsporidian Infection}

Dendritic cells are essential antigen presentation cells and thus function as a bridge between innate and adaptive immune systems (Mellman and Steinman, 2001). Antigens presented by DCs to $\mathrm{T}$ cells promote the adaptive immunity via activating naïve lymphocytes into effector $\mathrm{T}$ cells, which will significantly boost immunity against the infection (Steinman and Hemmi, 2006; Bieber and Autenrieth, 2020). Besides, DCs can secrete many cytokines, such as IL-12 and IFNs, which will trigger adaptive immune responses against the foreigner invasions (Mellman and Steinman, 2001; Trinchieri, 2003; von Stebut and Tenzer, 2018).

It was reported that IFN- $\gamma$ and IL-12 play vital roles in DCs response against microsporidian infection. The IFN $-\gamma$ secreted by DCs is important for priming the gut intraepithelial lymphocytes response (IEL) against $E$. cuniculi infection. Murine DCs lacking IFN $-\gamma$ failed to induce IEL response and led to ineffective suppression of the infection (Moretto et al., 2007, 2012). The IL12 is also an important cytokine responding to microsporidian infection. The mutant mice lacking IL-12 was found to be susceptible to the infection (Khan and Moretto, 1999), and CD8+
T cells showed poor immune response (Moretto et al., 2010). In infected DCs, IL-12 production was strongly induced, while the $\mathrm{p} 40^{-/-}$DCs lacking IL-12 failed to develop robust CD8+ T cell-mediated immune response to E. cuniculi infection (Moretto et al., 2010). Studies also showed that the IL-12 can be induced during early infection of DC by E. cuniculi, suggesting that IL12 is important to the initiation of innate immunity (Lawlor et al., 2010; Figure 2). Moreover, the PRRs of DCs, like Tolllike receptors (TLRs), are crucial for pathogen-recognition. It was shown that TLR4 is a key factor for DCs response (Figure 2), and is also essential for the expression of costimulatory molecules (CD80, CD86, and MHC class II), which induce optimal antigenspecific CD8+ T cells response to E. cuniculi infection (Lawlor et al., 2010). In Enterocytozoon bieneusi infection, however, TLR4 is not required for DCs response, but the myeloid differentiation factor 88 (MyD88) involved in Toll-like signaling pathway is needed (Zhang et al., 2011). Therefore, DCs probably recognize different microsporidia via different TLRs.

On the other hand, the differentiation of DCs was found to be inhibited by microsporidia via an IL-6-dependent mechanism so that the parasites can escape from stronger immune defense (Bernal et al., 2016; Figure 3). In addition, the ability of priming 


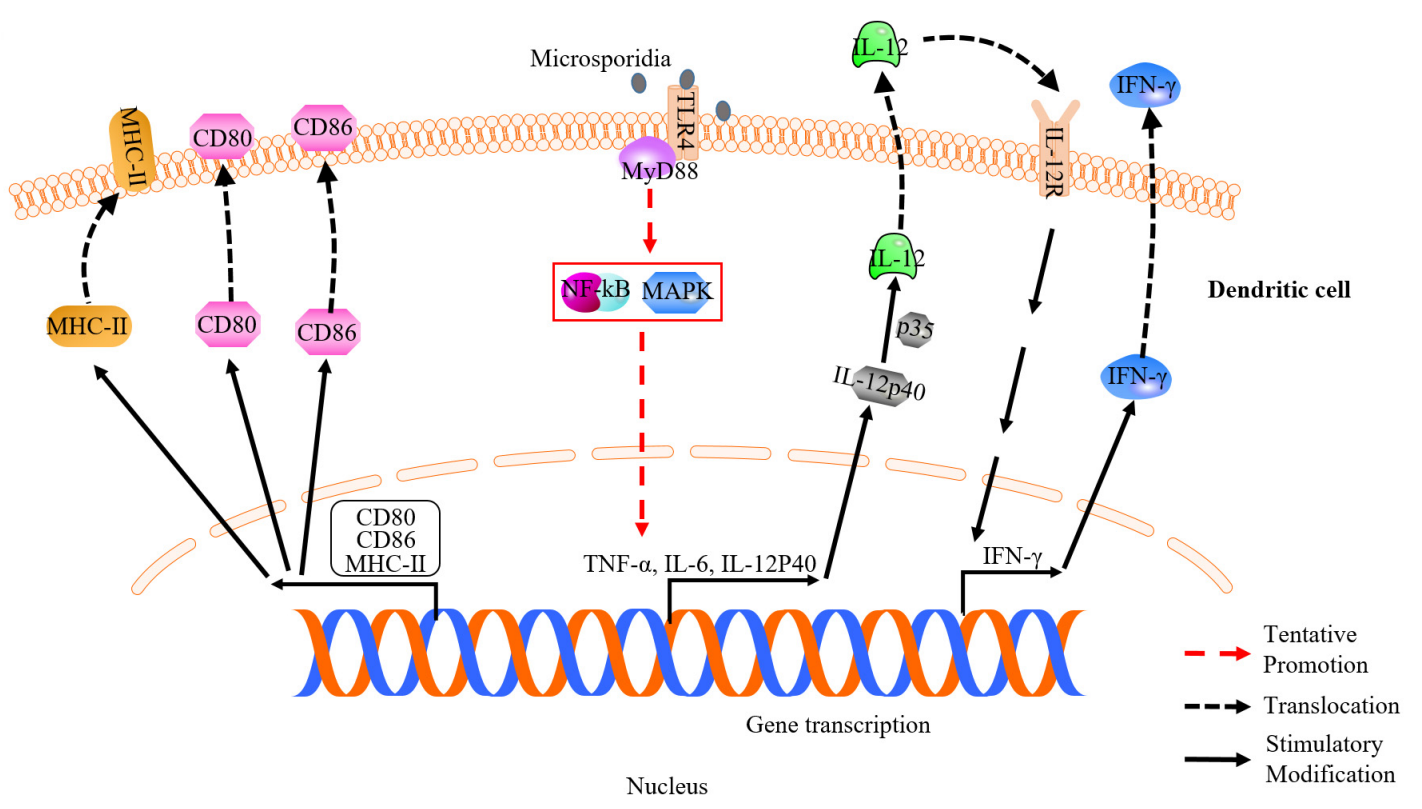

FIGURE 2 | Dendritic cell (DC) response against microsporidian infection. Surface molecules of CD80, CD86, MHC-II and toll-like receptor 4 are up-regulated in infected DC. Upregulation of CD80, CD86, and MHC-II is essential for induction of optimal T-cell response. DC can recognize microsporidia via TLR4. IL-12 and IFN- $\gamma$ secreted by DC help to optimize and prime effector T cell immune response, respectively.

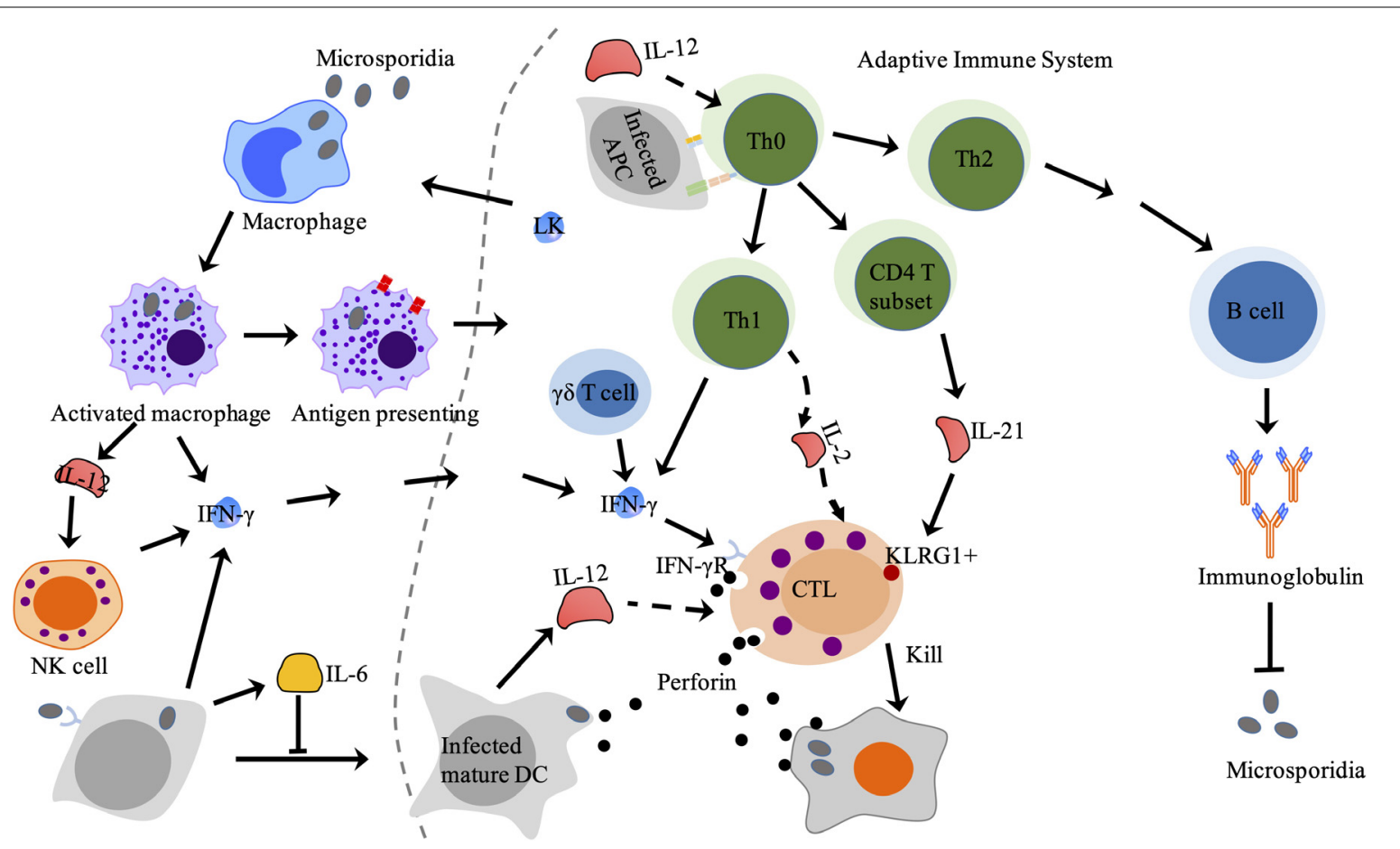

FIGURE 3 | Adaptive immune response against microsporidia in mammals. CTL is activated by APC and cytokines from innate immune cells and Th cell and then lyses target cell via perforin-dependent cytotoxicity. Antibodies produced by effector B lymphocytes can partially block microsporidian infection. LK produced by lymphocytes stimulates macrophage to secret IFN- $\gamma$. LK, lymphokines; CTL, cytotoxic T lymphocytes; Th cell, helper T cell; APC, antigen presenting cell.

antigen-specific $\mathrm{T}$ cell response in aged host decreases at the microsporidia-infected gut mucosal site (Moretto et al., 2008; Gigley and Khan, 2011). The maturation of DCs can be inhibited by the programmed death-ligand 1 (PD-L1), which expression is increased in aged mice leading to decrease of mature DCs and T cells immunity (Gigley and Khan, 2011). This probably is a 
reason why the aged is susceptible to microsporidian infection (Lores et al., 2002).

\section{NKs Response to Microsporidian Infection}

The NKs are a type of cytotoxic lymphocytes and critical to the innate immune system. NKs can not only lyse infected cells, but also secret cytokines like IFN- $\gamma$ to induce immunity of antigen specific $T$ cells (Yokoyama, 2005). It was found that the activity of NKs was enhanced in mice infected with E. cuniculi (Niederkorn et al., 1983), and the number of NKs increased upon early infection of E. cuniculi but decreased to a normal level in late infection stage (Khan et al., 1999). Further studies indicated that NKs can also produce IFN- $\gamma$ after stimulated by IL-12 secreted by macrophages (Braunfuchsova et al., 1999; Salat et al., 2004; Figure 3).

\section{Intraepithelial Lymphocytes Response to Microsporidian Infection}

The intestinal mucosa is an important defense line against microsporidia by inducing strong intraepithelial lymphocytes (IELs) response (Moretto et al., 2004, 2007, 2012). The population of IELs accompanied with the secretion of cytokines, such as IFN$\gamma$ and IL-10, rapidly increases in early infection by E. cuniculi. And the activated IELs are cytotoxic to infected syngeneic macrophages, which can kill more than $60 \%$ antigen-specific target cells (Moretto et al., 2004). These findings indicated that the early expansion of IELs not only serves as the first defense line, but also offers immunoregulators. Besides, the IFN- $\gamma$ produced by DCs from mucosal sites is crucial for evoking antigenspecific IEL responses against microsporidia in the small intestine (Moretto et al., 2007).

\section{Apoptosis Response to Microsporidian Infection}

Apoptosis is a form of programmed cell death that also responses to pathogen infection and plays significant roles in the control of the immune response (Knodler and Finlay, 2001; Luder et al., 2001; Higes et al., 2013).

Intracellular parasites like microsporidia and Toxoplasma gondii can suppress host apoptosis in order to have more time for proliferation (Nash et al., 1998; Heussler et al., 2001; Higes et al., 2013; He et al., 2015; Kurze et al., 2015; Sinpoo et al., 2017; Sokolova et al., 2019). Microsporidia can inhibit host apoptosis via modulating apoptosis-related proteins. Buffy and BIRC5 are two host factors that suppress apoptosis. The buffy is a Bcl2 like protein and can inhibit caspase-dependent cell death by activating downstream gene expressions in Drosophila (Quinn et al., 2003). And the BIRC5 is a member of the inhibitors of apoptosis family (IAP), which can inhibit caspase activation to reduce apoptosis (Heussler et al., 2001; Martin-Hernandez et al., 2017). Microsporidian Nosema ceranae and Nosema apis were reported to suppress host apoptosis via up-regulating expression of the buffy and BIRC5 (Higes et al., 2013; Martin-Hernandez et al., 2017; Figure 4A). In mitochondria-mediated apoptosis pathway, the tumor suppressor protein p53 is activated for recruiting Bax (pro-apoptosis protein member of Bcl-2 family) to mitochondrial membrane. Then the Bax promotes the release of cytochrome c (CYT-C) from mitochondria to cytoplasm, where the CYT-C binds to apoptosis protease activated factor 1 (APAF1). Finally, the APAF1, cytochrome $c$ and caspase- 9 assemble and form a protein complex to facilitate cell death (Heussler et al., 2001; Figure 4A). Microsporidian Nosema bombycis can also inhibit host apoptosis by down-regulating the expression of apaf1 and cyt-c and up-regulating the expression of buffy, so that reduce caspase-3 activity and inhibit host apoptosis (He et al., 2015). Besides, Encephalitozoon infection can suppress apoptosis of Vero cells by inhibiting the cleavage of caspase3, phosphorylation and translocation of p53 (del Aguila et al., 2006; Figure 4B). In the apoptosis process, the p53 activated the expressions of $p 21$ and Bax to induce apoptosis (Miyashita et al., 1994). However, expressional changes of the $B c l-2$ and $B a x$ are not observed in Encephalitozoon infected Vero cells for unknown reasons (del Aguila et al., 2006). A previous study showed that $T$. gondii prevented the activation and cytosol-mitochondrial targeting of Bax but not the protein levels to inhibit host apoptosis (Hippe et al., 2009). It is possible that Encephalitozoon also utilize mechanisms similar to that of the T. gondii to modulate host Bax.

In a recent study, the expressions of 84 apoptosis-related genes were investigated in E. cuniculi and Vittaforma corneae infected THP1 cell line. As a result, both pathogens can manipulate intrinsic apoptosis pathway (Sokolova et al., 2019). The assayed pro-apoptosis genes including LTA, CARD8, TRADD, BAX, CASP3, CASP1, CASP4, CASP9, BP2, DARK1, and BCLAF1 are all down-regulated, while some anti-apoptosis genes, such as ABL1, BAG1, BAG3, BCL2, TNFRSF1A, and CD4OLG, are all up-regulated upon infection. This study suggests that host apoptosis pathway is deeply modulated by the pathogen. Similar to Encephalitozoon, other intracellular parasites, such as T. gondii, Trypanosoma cruzi, and Cryptosporidium parvum, were also found to inhibit host apoptosis via similar mechanisms (Heussler et al., 2001; Luder et al., 2001; Mammari et al., 2019), indicating that intracellular pathogens can modulate host apoptosis pathway with similar or conserved strategies.

\section{Antimicrobial Peptides Response to Microsporidian Infection}

Antimicrobial peptides are important components of the host innate immune system. It was reported that lactoferrin (Lf), lysozyme (Lz), human beta defensin 2 (HBD2), human alpha defensin 5 (HD5), and human alpha defensin 1 (HNP1) are capable of inhibiting microsporidian spore germination and reducing enterocytes infection (Leitch and Ceballos, 2008). For example, the germination of Encephalitozoon hellem spore can be inhibited by HNP1. And the germination of Anncaliia algerae spore can also be blocked by Lf, HBD2, HD5, and HNP1 (Leitch and Ceballos, 2008). However, this inhibitory ability of antimicrobial peptides is not applicable to all microsporidian species. The germination of Encephalitozoon intestinalis spores cannot be inhibited by any of the peptides listed above (Leitch and Ceballos, 2008). It is likely that microsporidia have different germination mechanisms. 


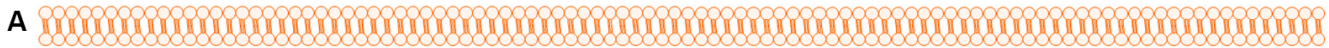
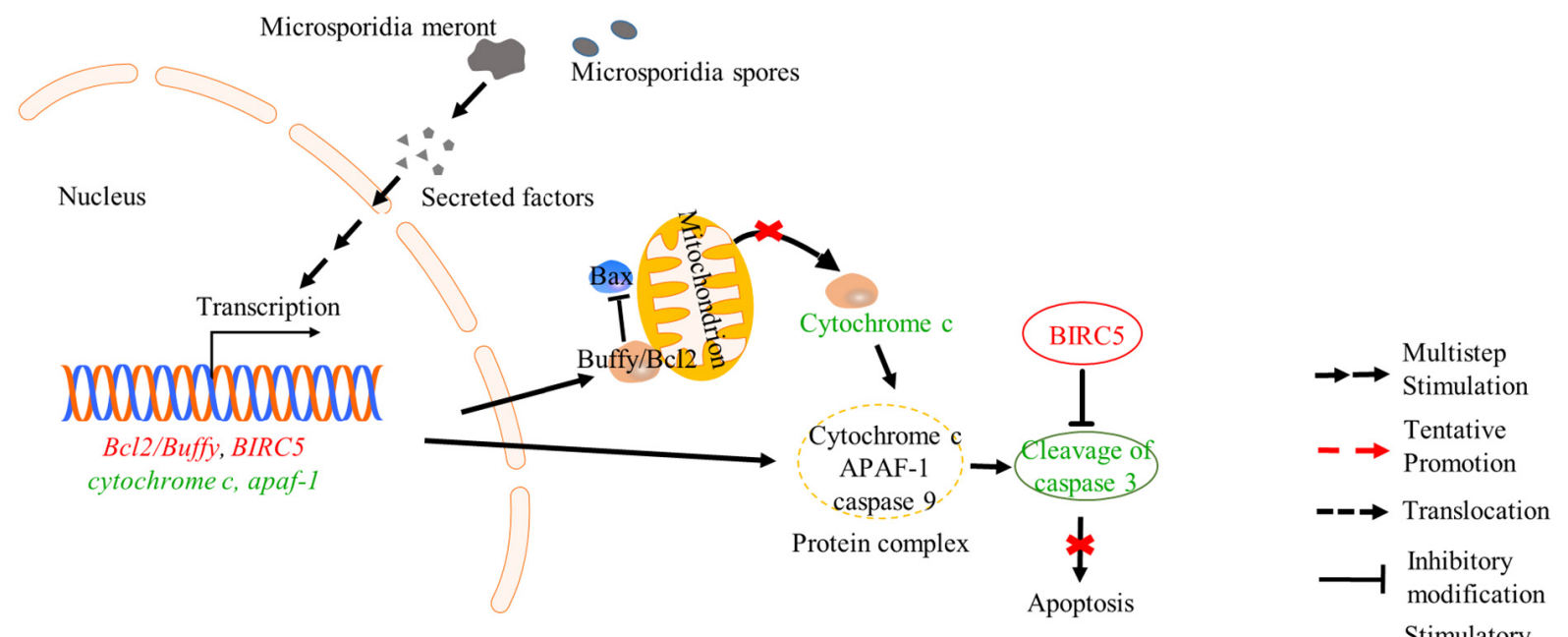

modification Stimulatory modification

$\rightarrow$ Block

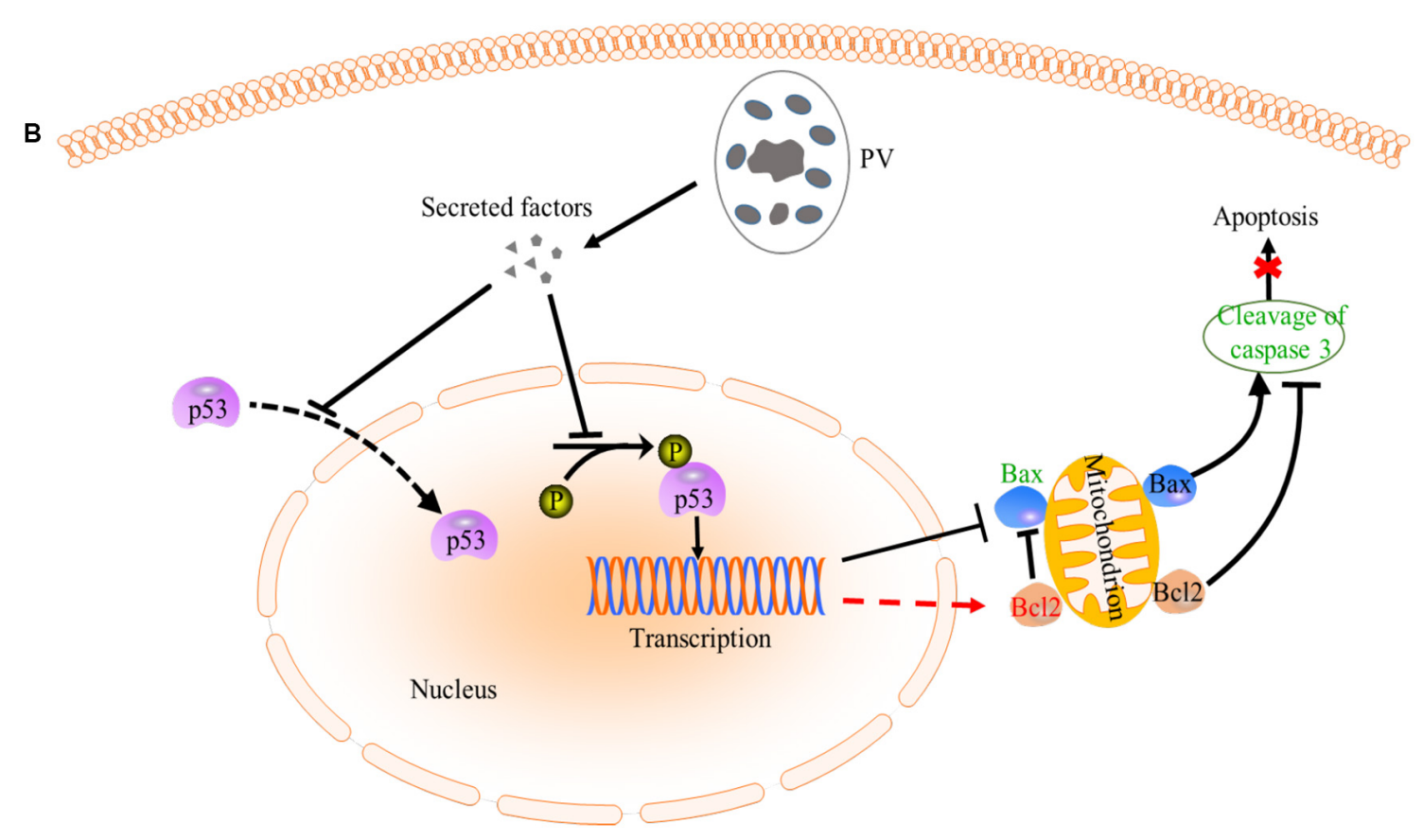

FIGURE 4 | Inhibition of apoptosis by microsporidia. (A) Microsporidian species which directly expose to host cytoplasm can inhibit the release of cytochrome $\mathrm{C}$ (CYT-C) by up-regulating the expression of Bcl2/Buffy. Besides, down-regulated expression of cyt-c and apaf-1 may cause reduction of cytochrome-APAF1-Caspase 9 complexes, which decrease cleavage activity of caspase 3 . And BIRC5 belongs to a member of IAP which can inhibit the capase3 activation. These changes caused the inhibition of host apoptosis. (B) Microsporidia species which live inside PV can inhibit host apoptosis by decreasing the phosphorylation and nuclear translocation of p53, which also leads to suppression of cleavage activity of caspase 3 . words in red: up-regulated gene; Words in green: down-regulated gene; PV, parasitophorous vacuole.

\section{ADAPTIVE IMMUNE RESPONSE AGAINST MICROSPORIDIAN INFECTION}

Adaptive immunity is broader and more efficient protection against non-self antigens than innate immune system. Adaptive immunity involves T lymphocytes-mediated cellular immunity and B lymphocytes-mediated humoral immunity, which have a tightly regulated interplay with antigen-presenting cells and facilitate the pathogen-specific elimination (Bonilla and Oettgen, 2010). When the innate immunity fails to block pathogen invasion, the adaptive immunity with production of antibodies and cytotoxic $\mathrm{T}$ lymphocytes (CTLs) will be triggered to 
resolve the infection. And $\mathrm{T}$ cell-mediated immunity plays a principal role in protection against microsporidia lethal infection (Valencakova and Halanova, 2012).

\section{Humoral Immune Response to Microsporidian Infection}

Humoral immunity is a very effective way to scavenge pathogens from the host (Casadevall, 2018). Treatment of Vero E6 cells with anti-exospore monoclonal antibody $\mathrm{P} 5 / \mathrm{H} 1$ could reduce E. cuniculi infection in vitro. One explanation for the inhibition is that $\mathrm{P} 5 / \mathrm{H} 1$ neutralizes sensitive epitopes on E. cuniculi spores so that the growth of the pathogens was suppressed (Schmidt and Shadduck, 1984). Antibodies binding to spores led to macrophages making more efficient phagocytosis and increase oxidative burst (Sak et al., 2004). In addition, the P5/H1 could prolong the survival of microsporidia-infected SCID mice, which were reconstituted with CD4+ T lymphocytes (Sak et al., 2006). Further studies showed that the protective effect of the antibodies on SCID mice depends on IFN- $\gamma$ (Salat et al., 2008).

Microsporidia like E. cuniculi are able to induce a strong antibody response. Increase of $\operatorname{IgA}, \operatorname{IgM}$, and IgG were detected in infected mice (Cox, 1977; Sak and Ditrich, 2005; Omalu et al., 2007; Figure 3). However, these antibodies cannot protect IFN- $\gamma$ knockout mice and athymic BALB/c (nu/nu) from death upon E. cuniculi infection (Schmidt and Shadduck, 1983; Salat et al., 2004; Valencakova and Halanova, 2012), suggesting that the antibody alone is not powerful enough to completely clear the infection.

\section{T Cell-Mediated Immune Response to Microsporidian Infection}

$\mathrm{T}$ cell-mediated immune response in host is crucial for prevention of infection. CD4+ and CD8+ T cells were found induced in infected mice and rabbits (El Naas et al., 1999; Soto-Dominguez et al., 2020), and were important in resisting against microsporidia (de Moura et al., 2019). And among T cell population, the CD8 $+\mathrm{T}$ cell subtype plays a major role during infection (Moretto et al., 2004). However, the activation of CD8+ T cell is associated with other immune cells and cytokines (Moretto et al., 2010; Langanke Dos Santos et al., 2017). The CD4+ T cells can be activated by infection and will develop to effective $\mathrm{T}$ cells. The number of $\mathrm{CD} 4+\mathrm{T}$ cells increased upon microsporidian infection in mice (El Naas et al., 1999). In addition, spleen cells from wild mice inoculated with E. intestinalis were shown to have elevated levels of IFN- $\gamma$ and IL-2 (El Fakhry et al., 2001), which are cytokines secreted by Th1 and involved in activation of CD8+ T cells. Adoptive transfer of pure $\mathrm{CD} 4+\mathrm{T}$ cells can prolong the survival of SCID mice (Salat et al., 2006). However, adoptive transfer of $\mathrm{CD} 4+\mathrm{T}$ cells from IFN- $\gamma$ deficient mice cannot prolong the survival of SCID mice (Salat et al., 2008). These results indicate that $\mathrm{CD} 8+\mathrm{T}$ lymphocytes-independent protection against the infection can be mediated by CD4+ T lymphocytes and the protective immunity is mediated by IFN- $\gamma$, which is a potential activator of macrophages. In other studies, the co-inhibitory receptor killer-cell lectin like receptor G1 (KLRG1) was found to be expressed in NKs and antigen-experienced T cells (Henson and Akbar, 2009). During the response against E. cuniculi, the KLRG1+ T cell subset was the majority of polyfunctional effector CD8+ T cells (Bhadra et al., 2014). A more recent study demonstrated that IL- 21 secreted by the CD4+ T cells was important for inducing KLRG1 ${ }^{+}$effector CD8+ $\mathrm{T}$ cells against microsporidian infection (Moretto and Khan, 2016; Figure 3). These studies indicate that the $\mathrm{CD} 4+\mathrm{T}$ cells play roles against microsporidian infection. However, mice lacking $\mathrm{CD} 4+\mathrm{T}$ cell still can survive from microsporidian infection (Moretto et al., 2000), suggesting that $C D 4+T$ cell is not a key immune defense against the infection.

Strong CD8+ $\mathrm{T}$ cell responses were also observed during microsporidian infection (Khan et al., 1999). The $\mathrm{CD} 8^{-/-}$mice became more susceptible to E. cuniculi infection (Moretto et al., 2000). And SCID mice, deficient in T and B cells, reconstituted with $\mathrm{CD} 8+\mathrm{T}$ cell-contained splenocytes resolved the infection (Braunfuchsova et al., 2001; Salat et al., 2002). These results suggest that the CD8+ T lymphocytes play a crucial role in resisting against E. cuniculi. And this protection depends on the activity of CD8+ CTLs, which lead to lysis of infected cells by perforin pathway (Khan et al., 1999; Figure 3). Moreover, trigger of CD8 $+\mathrm{T}$ cells into CTLs had been documented. The activation of the CD8+ T cells can be evoked by CD4+ T cells. For example, mice lacking CD4+ $\mathrm{T}$ cells show a lower CTLs response to virus infection (Matloubian et al., 1994). However, $\mathrm{CD} 4+\mathrm{T}$ cell deficiency does not affect the effector CD8+ T cell responding against E. cuniculi infection (Moretto et al., 2000), suggesting CD4+ T cell is not the sole activator of CD8+ T cell response and another reason is associated with the route of infection (Moretto et al., 2004; de Moura et al., 2019). It was found that other immune cell types like DC, $\gamma \delta \mathrm{T}$ cell, and B-1 cell are also key roles in modulating the antigenspecific CD8+ T cell immunity (Moretto et al., 2001; Langanke Dos Santos et al., 2017). The $\gamma \delta \mathrm{T}$ cells were reported to be important for establishing primary immune response against pathogen infection by producing cytokines (Berguer and Ferrick, 1995; Ferrick et al., 1995; Figure 3). It was found that the $\gamma \delta \mathrm{T}$ cell significantly increases in early infection of mice by E. cuniculi, while lacking of $\gamma \delta \mathrm{T}$ cell causes down-regulation of CD8+ cell immune response (Moretto et al., 2001). In addition to $\gamma \delta \mathrm{T}$ cell, the B-1 cell was found to be able to decrease host susceptibility to E. cuniculi (da Costa et al., 2016). In microsporidia-infected BABL/c XID mice, which are B-1 cell deficient, the population of CD8+ T cell decreases compared with that of infected BABL/c mice (Langanke Dos Santos et al., 2017). This suggests that the $B-1$ cell can increase the immunity of the CD8+ T lymphocytes, in addition to increasing proinflammatory cytokines and modulating M1 prolife (Pereira et al., 2019). Probably, B-1 cell behaves as an APC to increase population of CD8 $+\mathrm{T}$ cell and promotes the activation of $\mathrm{CD} 4+$ T cell (Hardy, 2006; Margry et al., 2013). Besides, the CD8+ T cell response can also be activated by DCs-secreted IL-12 during infection by E. cuniculi (Moretto et al., 2010; Figure 3). These findings demonstrate that $\mathrm{CD} 8+\mathrm{T}$ cell is vital in responses against microsporidia and also explain why $\mathrm{CD} 8+\mathrm{T}$ cell can be induced in the absence of the CD4+ T cell. 
In general, $\mathrm{T}$ cell-mediated immune protection is essential for elimination of microsporidian infection. However, microsporidian spores still can remain in some organs of immunocompetent mice and may become a source of infection onset (Kotkova et al., 2013; Sak et al., 2017). This raises an important question that how microsporidia escape the strong immunities.

\section{CONCLUSION}

The innate and adaptive immune systems play vital roles against microsporidian infection. Further understanding of host immune responses against the infection will greatly help with the diagnosis and treatment of microsporidiosis. The innate immune system not only directly resists the infection but also triggers the adaptive immunity. Innate immune cells, such as macrophages, DCs, $\gamma \delta$ $\mathrm{T}$ cell, and NKs, can control microsporidia to some extent, and also secret cytokines and chemokines to assist both the innate and adaptive immunities against the infection. The cytokine IL-12 and IFN- $\gamma$ can help to clear the parasite by activating related immune responses. However, early expression of IL10 is benefit for the pathogen growth by negatively regulating the IFN-gamma expression. Yet the relation between IL-10 and microsporidia remains to be clarified. Besides, it is worth noting that lymphokines can also activate macrophages to kill microsporidia (Schmidt and Shadduck, 1984; Figure 3). With the innate immunities, however, the host cell cannot completely clear microsporidia probably due to the evasive mechanism of the pathogens (Weidner, 1975; Bernal et al., 2016).

To completely clear the infection, the host needs to initiate the adaptive immunity. First of all, the CTL can be activated to restrict the proliferation of microsporidia by lysing infected cells via perforin pathway (Figure 3 ). In addition, increase of IgA, IgM, and IgG was observed in microsporidia-infected

\section{REFERENCES}

Abu-Akkada, S. S., El Kerdany, E. D. H., Mady, R. F., Diab, R. G., Khedr, G. A. E., Ashmawy, K. I., et al. (2015). Encephalitozoon cuniculi infection among immunocompromised and immunocompetent humans in Egypt. Iranian J. Parasitol. 10, 561-570.

Achbarou, A., Ombrouck, C., Gneragbe, T., Charlotte, F., Renia, L., Desportes-Livage, I., et al. (1996). Experimental model for human intestinal microsporidiosis in interferon gamma receptor knockout mice infected by Encephalitozoon intestinalis. Parasite Immunol. 18, 387-392. doi: 10.1046/j.1365-3024.1996.d01-128.x

Akiyoshi, D. E., Morrison, H. G., Lei, S., Feng, X., Zhang, Q., Corradi, N., et al. (2009). Genomic survey of the non-cultivatable opportunistic human pathogen, Enterocytozoon bieneusi. PLoS Pathog. 5:e1000261. doi: 10.1371/journal.ppat. 1000261

Berguer, R., and Ferrick, D. A. (1995). Differential production of intracellular gamma interferon in alpha beta and gamma delta T-cell subpopulations in response to peritonitis. Infect. Immun. 63, 4957-4958. doi: 10.1128/iai.63.12. 4957-4958.1995

Bernal, C. E., Zorro, M. M., Sierra, J., Gilchrist, K., Botero, J. H., Baena, A., et al. (2016). Encephalitozoon intestinalis inhibits dendritic cell differentiation through an IL-6-dependent mechanism. Front. Cell. Infect. Microbiol. 6:4. doi: $10.3389 /$ fcimb.2016.00004 mice (Cox, 1977; Sak and Ditrich, 2005; Omalu et al., 2007). Furthermore, specific antibodies have been found to have strong inhibitory effects against microsporidia (Sak et al., 2004, 2006). In the adaptive immunity, antibodies play important roles in resisting against microsporidia. However, humoral responses to microsporidian infection have not been clearly illuminated and further studies with microsporidia-infected mice models are needed.

In summary, the interactions between microsporidia and host immune systems have been further studied, but are far to be fully elucidated. For example, what are the key host cells and factors that confer the defense effects. And what are the mechanisms that microsporidia modulate host immune responses. Hopefully, genomics and proteomics studies on microsporidia have provided some important clues and candidates to dissect the questions (Katinka et al., 2001; Mittleider et al., 2002; Akiyoshi et al., 2009; Corradi et al., 2010; Reinke et al., 2017).

\section{AUTHOR CONTRIBUTIONS}

TL and ZZ contributed to conception and design of the study. TL and $\mathrm{YH}$ wrote the first draft of the manuscript. HG, JX, JL, BH, JB, and GP wrote sections of the manuscript. All authors contributed to manuscript revision, read and approved the submitted version.

\section{FUNDING}

This work was supported by grants from the National Natural Science Foundation of China (31772678, 31472151, and 31770159), Natural Science Foundation of Chongqing, China (cstc2019yszx-jcyjX0010), and Fundamental Research Funds for the Central Universities (XDJK2019TY002).

Beutler, B. (2004). Innate immunity: an overview. Mol. Immunol. 40, 845-859. doi: 10.1016/j.molimm.2003.10.005

Bhadra, R., Moretto, M. M., Castillo, J. C., Petrovas, C., Ferrando-Martinez, S., Shokal, U., et al. (2014). Intrinsic TGF-beta signaling promotes age-dependent CD8+ T cell polyfunctionality attrition. J. Clin. Invest. 124, 2441-2455. doi: 10.1172/JCI70522

Bieber, K., and Autenrieth, S. E. (2020). Dendritic cell development in infection. Mol. Immunol. 121, 111-117. doi: 10.1016/j.molimm.2020.02.015

Bonilla, F. A., and Oettgen, H. C. (2010). Adaptive immunity. J. Allergy Clin. Immunol. 125, S33-S40. doi: 10.1016/j.jaci.2009.09.017

Braunfuchsova, P., Kopecky, J., Ditrich, O., and Koudela, B. (1999). Cytokine response to infection with the microsporidian, Encephalitozoon cuniculi. Folia Parasitol. (Praha) 46, 91-95.

Braunfuchsova, P., Salat, J., and Kopecky, J. (2001). CD8+ T lymphocytes protect SCID mice against Encephalitozoon cuniculi infection. Int. J. Parasitol. 31, 681-686. doi: 10.1016/s0020-7519(01)00134-5

Cali, A., Becnel, J. J., and Takvorian, P. M. (2017). "Microsporidia," in Handbook of the Protists, eds J. M. Archibald, A. G. B. Simpson, and C. H. Slamovits (Cham: Springer International Publishing), 1559-1618.

Casadevall, A. (2018). Antibody-based vaccine strategies against intracellular pathogens. Curr. Opin. Immunol. 53, 74-80. doi: 10.1016/j.coi.2018.04.011

Corradi, N., Pombert, J. F., Farinelli, L., Didier, E. S., and Keeling, P. J. (2010). The complete sequence of the smallest known nuclear genome from the 
microsporidian Encephalitozoon intestinalis. Nat. Commun. 1:77. doi: 10.1038/ ncomms 1082

Couper, K. N., Blount, D. G., and Riley, E. M. (2008). IL-10: the master regulator of immunity to infection. J. Immunol. 180, 5771-5777. doi: 10.4049/jimmunol. 180.9.5771

Cox, J. C. (1977). Altered immune responsiveness associated with Encephalitozoon cuniculi infection in rabbits. Infect. Immun. 15, 392-395. doi: 10.1128/iai.15.2. 392-395.1977

da Costa, L. F. V., Alvares-Saraiva, A. M., Dell'Armelina Rocha, P. R., SpadacciMorena, D. D., Perez, E. C., Mariano, M., et al. (2016). B-1 cell decreases susceptibility to encephalitozoonosis in mice. Immunobiology 222, 218-227. doi: 10.1016/j.imbio.2016.09.018

de Moura, M. L. C., Alvares-Saraiva, A. M., Pérez, E. C., Xavier, J. G., Spadacci-Morena, D. D., Moysés, C. R. S., et al. (2019). Cyclophosphamide treatment mimics sub-lethal infections with Encephalitozoon intestinalis in immunocompromised individuals. Front. Microbiol. 10:2205. doi: 10.3389/ fmicb.2019.02205

del Aguila, C., Izquierdo, F., Granja, A. G., Hurtado, C., Fenoy, S., Fresno, M., et al. (2006). Encephalitozoon microsporidia modulates p53-mediated apoptosis in infected cells. Int. J. Parasitol. 36, 869-876. doi: 10.1016/j.ijpara.2006.04.002

Didier, E. S. (1995). Reactive nitrogen intermediates implicated in the inhibition of Encephalitozoon cuniculi (phylum microspora) replication in murine peritoneal macrophages. Parasite Immunol. 17, 405-412. doi: 10.1111/j.1365-3024.1995. tb00908.x

Didier, E. S., Bowers, L. C., Martin, A. D., Kuroda, M. J., Khan, I. A., and Didier, P. J. (2010). Reactive nitrogen and oxygen species, and iron sequestration contribute to macrophage-mediated control of Encephalitozoon cuniculi (Phylum Microsporidia) infection in vitro and in vivo. Microbes Infect. 12, 1244-1251. doi: 10.1016/j.micinf.2010.09.010

Didier, E. S., and Shadduck, J. A. (1994). IFN-gamma and LPS induce murine macrophages to kill Encephalitozoon cuniculi in vitro. J. Eukaryot. Microbiol. 41:34S.

El Fakhry, Y., Achbarou, A., Desportes, I., and Mazier, D. (2001). Resistance to Encephalitozoon intestinalis is associated with interferon-gamma and interleukin-2 cytokines in infected mice. Parasite Immunol. 23, 297-303. doi: 10.1046/j.1365-3024.2001.00386.x

El Fakhry, Y., Achbarou, A., Desportes-Livage, I., and Mazier, D. (1998). Encephalitozoon intestinalis: humoral responses in interferon-gamma receptor knockout mice infected with a microsporidium pathogenic in AIDS patients. Exp. Parasitol. 89, 113-121. doi: 10.1006/expr.1998.4267

El Naas, A., Levkut, M., Revajova, V., Levkutova, M., Hipikova, V., and Letkova, V. (1999). Immune response to Encephalitozoon cuniculi infection in laboratory mice. Vet. Parasitol. 82, 137-143. doi: 10.1016/s0304-4017(98)00261-1

Fayer, R., and Santin-Duran, M. (2014). "Epidemiology of microsporidia in human infections," in Microsporidia: Pathogens of Opportunity, 1st Edn, eds L. M. Weiss and J. J. Becnel (Oxford: Wiley Blackwell), 135-164. doi: 10.1002/ 9781118395264.ch3

Ferrick, D. A., Schrenzel, M. D., Mulvania, T., Hsieh, B., Ferlin, W. G., and Lepper, H. (1995). Differential production of interferon-gamma and interleukin-4 in response to Th1 - and Th2-stimulating pathogens by gamma delta $\mathrm{T}$ cells in vivo. Nature 373, 255-257. doi: 10.1038/373255a0

Fischer, J., Suire, C., and Hale-Donze, H. (2008a). Toll-like receptor 2 recognition of the microsporidia Encephalitozoon spp. induces nuclear translocation of NFkappaB and subsequent inflammatory responses. Infect. Immun. 76, 4737-4744. doi: 10.1128/IAI.00733-08

Fischer, J., Tran, D., Juneau, R., and Hale-Donze, H. (2008b). Kinetics of Encephalitozoon spp. infection of human macrophages. J. Parasitol. 94, 169175. doi: 10.1645/GE-1303.1

Fischer, J., West, J., Agochukwu, N., Suire, C., and Hale-Donze, H. (2007). Induction of host chemotactic response by Encephalitozoon spp. Infect. Immun. 75, 1619-1625. doi: 10.1128/IAI.01535-06

Franzen, C. (2005). How do microsporidia invade cells? Folia Parasitol. (Praha) 52, 36-40. doi: 10.14411/fp.2005.005

Franzen, C., Hartmann, P., and Salzberger, B. (2005a). Cytokine and nitric oxide responses of monocyte-derived human macrophages to microsporidian spores. Exp. Parasitol. 109, 1-6. doi: 10.1016/j.exppara.2004.10.001

Franzen, C., Müller, A., Hartmann, P., and Salzberger, B. (2005b). Cell invasion and intracellular fate of Encephalitozoon cuniculi
(Microsporidia). Parasitology 130(Pt 3), 285-292. doi: 10.1017/s0031182004 $00633 \mathrm{x}$

Ghosh, K., and Weiss, L. M. (2012). T cell response and persistence of the microsporidia. FEMS Microbiol. Rev. 36, 748-760. doi: 10.1111/j.1574-6976. 2011.00318.x

Ghoyounchi, R., Mahami-Oskouei, M., Rezamand, A., Spotin, A., Aminisani, N., Nami, S., et al. (2019). Molecular phylodiagnosis of Enterocytozoon bieneusi and Encephalitozoon intestinalis in children with cancer: microsporidia in malignancies as an emerging opportunistic infection. Acta Parasitol. 64, 103111. doi: 10.2478/s11686-018-00012-w

Gigley, J. P., and Khan, I. A. (2011). Plasmacytoid DC from aged mice down-regulate $\mathrm{CD} 8 \mathrm{~T}$ cell responses by inhibiting $\mathrm{cDC}$ maturation after Encephalitozoon cuniculi infection. PLoS One 6:e20838. doi: 10.1371/journal. pone.0020838

Gonzalez-Machorro, J. R., Rodriguez-Tovar, L. E., Gomez-Flores, R., SotoDominguez, A., Rodriguez-Rocha, H., Garcia-Garcia, A., et al. (2019). Increased phagocytosis and growth inhibition of Encephalitozoon cuniculi by LPSactivated J774A.1 murine macrophages. Parasitol. Res. 118, 1841-1848. doi: 10.1007/s00436-019-06310-0

Han, B., Takvorian, P. M., and Weiss, L. M. (2020). Invasion of host cells by microsporidia. Front. Microbiol. 11:172. doi: 10.3389/fmicb.2020.00172

Han, B., and Weiss, L. M. (2017). Microsporidia: obligate intracellular pathogens within the fungal kingdom. Microbiol. Spectr. 5:10.1128/microbiolspec.FUNK0018-2016. doi: 10.1128/microbiolspec.FUNK-0018-2016

Hardy, R. R. (2006). B-1 B cells: development, selection, natural autoantibody and leukemia. Curr. Opin. Immunol. 18, 547-555. doi: 10.1016/j.coi.2006.07.010

He, X., Fu, Z., Li, M., Liu, H., Cai, S., Man, N., et al. (2015). Nosema bombycis (Microsporidia) suppresses apoptosis in $\mathrm{BmN}$ cells (Bombyx mori). Acta Biochim. Biophys. Sin. (Shanghai) 47, 696-702. doi: 10.1093/abbs/ gmv062

Henson, S. M., and Akbar, A. N. (2009). KLRG1-more than a marker for T cell senescence. Age (Dordr) 31, 285-291. doi: 10.1007/s11357-009-9100-9

Heussler, V. T., Kuenzi, P., and Rottenberg, S. (2001). Inhibition of apoptosis by intracellular protozoan parasites. Int. J. Parasitol. 31, 1166-1176. doi: 10.1016/ s0020-7519(01)00271-5

Higes, M., Juarranz, A., Dias-Almeida, J., Lucena, S., Botias, C., Meana, A., et al. (2013). Apoptosis in the pathogenesis of Nosema ceranae (Microsporidia: Nosematidae) in honey bees (Apis mellifera). Environ. Microbiol. Rep. 5, 530536. doi: 10.1111/1758-2229.12059

Hippe, D., Weber, A., Zhou, L., Chang, D. C., Hacker, G., and Luder, C. G. (2009). Toxoplasma gondii infection confers resistance against BimS-induced apoptosis by preventing the activation and mitochondrial targeting of pro-apoptotic Bax. J. Cell. Sci. 122(Pt 19), 3511-3521. doi: 10.1242/jcs.050963

Katinka, M. D., Duprat, S., Cornillot, E., Metenier, G., Thomarat, F., Prensier, G., et al. (2001). Genome sequence and gene compaction of the eukaryote parasite Encephalitozoon cuniculi. Nature 414, 450-453. doi: 10.1038/35106579

Khan, I. A., and Moretto, M. (1999). Role of gamma interferon in cellular immune response against murine Encephalitozoon cuniculi infection. Infect. Immun. 67, 1887-1893. doi: 10.1128/.67.4.1887-1893.1999

Khan, I. A., Moretto, M., and Weiss, L. M. (2001). Immune response to Encephalitozoon cuniculi infection. Microbes Infect. 3, 401-405. doi: 10.1016/ s1286-4579(01)01397-1

Khan, I. A., Schwartzman, J. D., Kasper, L. H., and Moretto, M. (1999). CD8+ CTLs are essential for protective immunity against Encephalitozoon cuniculi infection. J. Immunol. 162, 6086-6091.

Knodler, L. A., and Finlay, B. B. (2001). Salmonella and apoptosis: to live or let die? Microbes Infect. 3, 1321-1326. doi: 10.1016/s1286-4579(01)01493-9

Kotkova, M., Sak, B., Kvetonova, D., and Kvac, M. (2013). Latent microsporidiosis caused by Encephalitozoon cuniculi in immunocompetent hosts: a murine model demonstrating the ineffectiveness of the immune system and treatment with albendazole. PLoS One 8:e60941. doi: 10.1371/journal.pone.0060941

Kurze, C., Le Conte, Y., Dussaubat, C., Erler, S., Kryger, P., Lewkowski, O., et al. (2015). Nosema tolerant honeybees (Apis mellifera) escape parasitic manipulation of apoptosis. PLoS One 10:e0140174. doi: 10.1371/journal.pone. 0140174

Langanke Dos Santos, D., Alvares-Saraiva, A. M., Xavier, J. G., Spadacci-Morena, D. D., Peres, G. B., Dell'Armelina Rocha, P. R., et al. (2017). B-1 cells upregulate CD8 $\mathrm{T}$ lymphocytes and increase proinflammatory cytokines serum levels in 
oral encephalitozoonosis. Microbes Infect. 20, 196-204. doi: 10.1016/j.micinf. 2017.11.004

Lawlor, E. M., Moretto, M. M., and Khan, I. A. (2010). Optimal CD8 T-cell response against Encephalitozoon cuniculi is mediated by Toll-like receptor 4 upregulation by dendritic cells. Infect. Immun. 78, 3097-3102. doi: 10.1128/IAI. 00181- 10

Leitch, G. J., and Ceballos, C. (2008). A role for antimicrobial peptides in intestinal microsporidiosis. Parasitology 136, 175-181. doi: 10.1017/s0031182008005313

Li, W., Feng, Y., Zhang, L., and Xiao, L. (2019). Potential impacts of host specificity on zoonotic or interspecies transmission of Enterocytozoon bieneusi. Infect. Genet. Evol. 75:104033. doi: 10.1016/j.meegid.2019.104033

Lores, B., Lopez-Miragaya, I., Arias, C., Fenoy, S., Torres, J., and del Aguila, C. (2002). Intestinal microsporidiosis due to Enterocytozoon bieneusi in elderly human immunodeficiency virus-negative patients from Vigo, Spain. Clin. Infect. Dis. 34, 918-921. doi: 10.1086/339205

Luder, C. G., Gross, U., and Lopes, M. F. (2001). Intracellular protozoan parasites and apoptosis: diverse strategies to modulate parasite-host interactions. Trends Parasitol. 17, 480-486. doi: 10.1016/s1471-4922(01)02016-5

Mammari, N., Halabi, M. A., Yaacoub, S., Chlala, H., Darde, M. L., and Courtioux, B. (2019). Toxoplasma gondii modulates the host cell responses: an overview of apoptosis pathways. Biomed. Res. Int. 2019:6152489. doi: 10.1155/2019/ 6152489

Margry, B., Wieland, W. H., van Kooten, P. J., van Eden, W., and Broere, F. (2013). Peritoneal cavity B-1a cells promote peripheral CD4+ T-cell activation. Eur. J. Immunol. 43, 2317-2326. doi: 10.1002/eji.201343418

Martinez, F. O., and Gordon, S. (2014). The M1 and M2 paradigm of macrophage activation: time for reassessment. F1000Prime Rep. 6:13. doi: 10.12703/P6-13

Martin-Hernandez, R., Higes, M., Sagastume, S., Juarranz, A., Dias-Almeida, J., Budge, G. E., et al. (2017). Microsporidia infection impacts the host cell's cycle and reduces host cell apoptosis. PLoS One 12:e0170183. doi: 10.1371/journal. pone. 0170183

Mathews, A., Hotard, A., and Hale-Donze, H. (2009). Innate immune responses to Encephalitozoon species infections. Microbes Infect. 11, 905-911. doi: 10.1016/j. micinf.2009.06.004

Matloubian, M., Concepcion, R. J., and Ahmed, R. (1994). CD4+ T cells are required to sustain $\mathrm{CD} 8+$ cytotoxic $\mathrm{T}$-cell responses during chronic viral infection. J. Virol. 68, 8056-8063. doi: 10.1128/jvi.68.12.8056-8063.1994

Mellman, I., and Steinman, R. M. (2001). Dendritic cells: specialized and regulated antigen processing machines. Cell 106, 255-258. doi: 10.1016/s0092-8674(01) 00449-4

Mittleider, D., Green, L. C., Mann, V. H., Michael, S. F., Didier, E. S., and Brindley, P. J. (2002). Sequence survey of the genome of the opportunistic microsporidian pathogen, Vittaforma corneae. J. Eukaryot. Microbiol. 49, 393-401. doi: 10.1111/ j.1550-7408.2002.tb00218.x

Miyashita, T., Krajewski, S., Krajewska, M., Wang, H. G., Lin, H. K., Liebermann, D. A., et al. (1994). Tumor suppressor p53 is a regulator of bcl-2 and bax gene expression in vitro and in vivo. Oncogene 9, 1799-1805.

Mor, S. M., Tumwine, J. K., Naumova, E. N., Ndeezi, G., and Tzipori, S. (2009). Microsporidiosis and malnutrition in children with persistent diarrhea, Uganda. Emerg. Infect. Dis. 15, 49-52. doi: 10.3201/eid1501.071536

Moretto, M., Casciotti, L., Durell, B., and Khan, I. A. (2000). Lack of CD4(+) T cells does not affect induction of CD8(+) T-cell immunity against Encephalitozoon cuniculi infection. Infect. Immun. 68, 6223-6232. doi: 10.1128/iai.68.11.62236232.2000

Moretto, M., Durell, B., Schwartzman, J. D., and Khan, I. A. (2001). Gamma delta $\mathrm{T}$ cell-deficient mice have a down-regulated CD8+ T cell immune response against Encephalitozoon cuniculi infection. J. Immunol. 166, 7389-7397. doi: 10.4049/jimmunol.166.12.7389

Moretto, M., Weiss, L. M., and Khan, I. A. (2004). Induction of a rapid and strong antigen-specific intraepithelial lymphocyte response during oral Encephalitozoon cuniculi infection. J. Immunol. 172, 4402-4409. doi: 10.4049/ jimmunol.172.7.4402

Moretto, M. M., and Khan, I. A. (2016). IL-21 is important for induction of KLRG1+ effector CD8 T cells during acute intracellular infection. J. Immunol. 196, 375-384. doi: 10.4049/jimmunol.1501258

Moretto, M. M., Khan, I. A., and Weiss, L. M. (2012). Gastrointestinal cell mediated immunity and the microsporidia. PLoS Pathog. 8:e1002775. doi: 10. 1371/journal.ppat.1002775
Moretto, M. M., Lawlor, E. M., and Khan, I. A. (2008). Aging mice exhibit a functional defect in mucosal dendritic cell response against an intracellular pathogen. J. Immunol. 181, 7977-7984. doi: 10.4049/jimmunol.181.11.7977

Moretto, M. M., Lawlor, E. M., and Khan, I. A. (2010). Lack of interleukin12 in p40-deficient mice leads to poor CD8+ T-cell immunity against Encephalitozoon cuniculi infection. Infect. Immun. 78, 2505-2511. doi: 10.1128/ IAI.00753-09

Moretto, M. M., Weiss, L. M., Combe, C. L., and Khan, I. A. (2007). IFN-gammaproducing dendritic cells are important for priming of gut intraepithelial lymphocyte response against intracellular parasitic infection. J. Immunol. 179, 2485-2492. doi: 10.4049/jimmunol.179.4.2485

Nash, P. B., Purner, M. B., Leon, R. P., Clarke, P., Duke, R. C., and Curiel, T. J. (1998). Toxoplasma gondii-infected cells are resistant to multiple inducers of apoptosis. J. Immunol. 160, 1824-1830.

Niederkorn, J. Y., Brieland, J. K., and Mayhew, E. (1983). Enhanced natural killer cell activity in experimental murine encephalitozoonosis. Infect. Immun. 41, 302-307. doi: 10.1128/iai.41.1.302-307.1983

Omalu, I. C., Duhlinska, D. D., Anyanwu, G. I., Pam, V. A., and Inyama, P. U. (2007). Immune responsiveness associated with experimental Encephalitozoon intestinalis infection in immunocompetent rats. Indian J. Med. Microbiol. 25, 209-213.

Pereira, A., Alvares-Saraiva, A. M., Konno, F. T. C., Spadacci-Morena, D. D., Perez, E. C., Mariano, M., et al. (2019). B-1 cell-mediated modulation of M1 macrophage profile ameliorates microbicidal functions and disrupt the evasion mechanisms of Encephalitozoon cuniculi. PLoS Negl. Trop. Dis. 13:e0007674. doi: 10.1371/journal.pntd.0007674

Popi, A. F., Lopes, J. D., and Mariano, M. (2004). Interleukin-10 secreted by B-1 cells modulates the phagocytic activity of murine macrophages in vitro. Immunology 113, 348-354. doi: 10.1111/j.1365-2567.2004.01969.x

Quinn, L., Coombe, M., Mills, K., Daish, T., Colussi, P., Kumar, S., et al. (2003). Buffy, a Drosophila Bcl-2 protein, has anti-apoptotic and cell cycle inhibitory functions. EMBO J. 22, 3568-3579. doi: 10.1093/emboj/cdg355

Reinke, A. W., Balla, K. M., Bennett, E. J., and Troemel, E. R. (2017). Identification of microsporidia host-exposed proteins reveals a repertoire of rapidly evolving proteins. Nat. Commun. 8:14023. doi: 10.1038/ncomms 14023

Rodriguez-Tovar, L. E., Castillo-Velazquez, U., Arce-Mendoza, A. Y., NevarezGarza, A. M., Zarate-Ramos, J. J., Hernandez-Vidal, G., et al. (2016). Interferon gamma and interleukin 10 responses in immunocompetent and immunosuppressed New Zealand white rabbits naturally infected with Encephalitozoon cuniculi. Dev. Comp. Immunol. 62, 82-88. doi: 10.1016/j.dci. 2016.05.003

Sak, B., and Ditrich, O. (2005). Humoral intestinal immunity against Encephalitozoon cuniculi (Microsporidia) infection in mice. Folia Parasitol. (Praha) 52, 158-162. doi: 10.14411/fp.2005.020

Sak, B., Kotkova, M., Hlaskova, L., and Kvac, M. (2017). Limited effect of adaptive immune response to control encephalitozoonosis. Parasite Immunol. 39:e12496. doi: $10.1111 /$ pim. 12496

Sak, B., Sakova, K., and Ditrich, O. (2004). Effects of a novel anti-exospore monoclonal antibody on microsporidial development in vitro. Parasitol. Res. 92, 74-80. doi: 10.1007/s00436-003-0988-1

Sak, B., Salat, J., Horka, H., Sakova, K., and Ditrich, O. (2006). Antibodies enhance the protective effect of CD4+ T lymphocytes in SCID mice perorally infected with Encephalitozoon cuniculi. Parasite Immunol. 28, 95-99. doi: 10.1111/j. 1365-3024.2005.00813.x

Salat, J., Braunfuchsova, P., Kopecky, J., and Ditrich, O. (2002). Role of CD4+ and CD8+ T lymphocytes in the protection of mice against Encephalitozoon intestinalis infection. Parasitol. Res. 88, 603-608. doi: 10.1007/s00436-0020620-9

Salat, J., Horka, H., Sak, B., and Kopecky, J. (2006). Pure CD4+ T lymphocytes fail to protect perorally infected SCID mice from lethal microsporidiosis caused by Encephalitozoon cuniculi. Parasitol. Res. 99, 682-686. doi: 10.1007/s00436-0060208-x

Salat, J., Jelinek, J., Chmelar, J., and Kopecky, J. (2008). Efficacy of gamma interferon and specific antibody for treatment of microsporidiosis caused by Encephalitozoon cuniculi in SCID mice. Antimicrob. Agents Chemother. 52, 2169-2174. doi: 10.1128/AAC.01506-07

Salat, J., Sak, B., Le, T., and Kopecky, J. (2004). Susceptibility of IFN-gamma or IL-12 knock-out and SCID mice to infection with two microsporidian 
species, Encephalitozoon cuniculi and E. intestinalis. Folia Parasitol. (Praha) 51, 275-282. doi: 10.14411/fp.2004.033

Schmidt, E. C., and Shadduck, J. A. (1983). Murine encephalitozoonosis model for studying the host-parasite relationship of a chronic infection. Infect. Immun. 40, 936-942. doi: 10.1128/iai.40.3.936-942.1983

Schmidt, E. C., and Shadduck, J. A. (1984). Mechanisms of resistance to the intracellular protozoan Encephalitozoon cuniculi in mice. J. Immunol. 133, 2712-2719.

Sinpoo, C., Paxton, R. J., Disayathanoowat, T., Krongdang, S., and Chantawannakul, P. (2017). Impact of Nosema ceranae and Nosema apis on individual worker bees of the two host species (Apis cerana and Apis mellifera) and regulation of host immune response. J. Insect. Physiol. 105, 1-8. doi: 10.1016/j.jinsphys.2017.12.010

Sokol, C. L., and Luster, A. D. (2015). The chemokine system in innate immunity. Cold Spring Harb. Perspect. Biol. 7:a016303. doi: 10.1101/cshperspect.a016303

Sokolova, Y. Y., Bowers, L. C., Alvarez, X., and Didier, E. S. (2019). Encephalitozoon cuniculi and Vittaforma corneae (Phylum Microsporidia) inhibit staurosporineinduced apoptosis in human THP-1 macrophages in vitro. Parasitology 146, 569-579. doi: 10.1017/S0031182018001968

Soto-Dominguez, A., Davila-Martinez, C., Castillo-Velazquez, U., NevarezGarza, A. M., Rodriguez-Rocha, H., Saucedo-Cardenas, O., et al. (2020). Variation of the CD4, CD8, and MHC II cell population in granulomas of immunocompetent and immunosuppressed rabbits in Encephalitozoon cuniculi infection. Comp. Immunol. Microbiol. Infect. Dis. 68:101387. doi: 10.1016/j. cimid.2019.101387

Steinman, R. M., and Hemmi, H. (2006). Dendritic cells: translating innate to adaptive immunity. Curr. Top. Microbiol. Immunol. 311, 17-58. doi: 10.1007/ 3-540-32636-7_2

Trinchieri, G. (2003). Interleukin-12 and the regulation of innate resistance and adaptive immunity. Nat. Rev. Immunol. 3, 133-146. doi: 10.1038/nri1001

Tumwine, J. K., Kekitiinwa, A., Nabukeera, N., Akiyoshi, D. E., Buckholt, M. A., and Tzipori, S. (2002). Enterocytozoon bieneusi among children with diarrhea attending mulago hospital in Uganda. Am. J. Trop. Med. Hyg. 67, 299-303. doi: 10.4269/ajtmh.2002.67.299

Turvey, S. E., and Broide, D. H. (2010). Innate immunity. J. Allergy Clin. Immunol. 125(2 Suppl. 2), S24-S32. doi: 10.1016/j.jaci.2009.07.016

Udonsom, R., Prasertbun, R., Mahittikorn, A., Chiabchalard, R., Sutthikornchai, C., Palasuwan, A., et al. (2019). Identification of Enterocytozoon bieneusi in goats and cattle in Thailand. BMC Vet. Res. 15:308. doi: 10.1186/s12917-0192054-y
Valencakova, A., and Halanova, M. (2012). Immune response to Encephalitozoon infection review. Comp. Immunol. Microbiol. Infect. Dis. 35, 1-7. doi: 10.1016/j. cimid.2011.11.004

von Stebut, E., and Tenzer, S. (2018). Cutaneous leishmaniasis: distinct functions of dendritic cells and macrophages in the interaction of the host immune system with Leishmania major. Int. J. Med. Microbiol. 308, 206-214. doi: 10.1016/j. ijmm.2017.11.002

Wang, Z.-D., Liu, Q., Liu, H.-H., Li, S., Zhang, L., Zhao, Y.-K., et al. (2018). Prevalence of Cryptosporidium, microsporidia and Isospora infection in HIVinfected people: a global systematic review and meta-analysis. Parasites Vectors 11, 28-28. doi: 10.1186/s13071-017-2558-x

Weidner, E. (1975). Interactions between Encephalitozoon cuniculi and macrophages. Parasitophorous vacuole growth and the absence of lysosomal fusion. $Z$ Parasitenkd, 47, 1-9. doi: 10.1007/BF004 18060

Weidner, E., and Sibley, L. D. (1985). Phagocytized intracellular microsporidian blocks phagosome acidification and phagosomelysosome fusion. J. Protozool. 32, 311-317. doi: 10.1111/j.1550-7408.1985. tb03056.x

Yokoyama, W. M. (2005). Natural killer cell immune responses. Immunol. Res. 32 317-325. doi: 10.1385/IR:32:1-3:317

Zhang, Q., Feng, X., Nie, W., Golenbock, D. T., Mayanja-Kizza, H., Tzipori, S., et al. (2011). MyD88-dependent pathway is essential for the innate immunity to Enterocytozoon bieneusi. Parasite Immunol. 33, 217-225. doi: 10.1111/j.13653024.2010.01269.x

Conflict of Interest: The authors declare that the research was conducted in the absence of any commercial or financial relationships that could be construed as a potential conflict of interest.

The reviewer LW declared a shared affiliation with the author $\mathrm{BH}$ at the time of review.

Copyright (c) $2020 \mathrm{Han}, \mathrm{Gao}, \mathrm{Xu}, \mathrm{Luo}, \mathrm{Han}, \mathrm{Bao}, \mathrm{Pan}, \mathrm{Li}$ and Zhou. This is an open-access article distributed under the terms of the Creative Commons Attribution License (CC BY). The use, distribution or reproduction in other forums is permitted, provided the original author(s) and the copyright owner(s) are credited and that the original publication in this journal is cited, in accordance with accepted academic practice. No use, distribution or reproduction is permitted which does not comply with these terms. 